\title{
Database of Siberian Vegetation (DSV)
}

\author{
Andrey Korolyuk \& Andrei Zverev
}

\begin{abstract}
A first variant of Database of Siberian Vegetation (DSV; GIVD ID AS-RU-002) was created in 1994 in the Laboratory of Geobotany of the Central Siberian Botanical Garden of the Siberian Branch of RAS (CSBG SB RAS). Now it is located at the Geosystem research laboratory of CSBG SB RAS and in Tomsk State University. DSV contains geobotanical relevés from Western and Eastern Siberia (incl. Republic Sakha - Yakutia), Altai-Sayan Mountain Country and Transbaicalia. Relevé sets from the Inner Mongolia province of China and the north of Kazakhstan Republic are also included but are not numerous. The main part of the database represents different types of steppe communities: meadow steppes, typical and desertified steppes, cryophyte steppes. Numerous sets comprise forests, meadows and wetlands as well as diverse intrazonal vegetation developed on rocky, sandy and salty habitats. The main purposes of database are developing a syntaxonomy of North Asia, analysing biogeography features of the Siberian flora and vegetation, development of plant indicator values and the ecological analysis of vegetation, vegetation mapping based on remote sensing data and creation of a Geographic Information System. DSV is supported by IBIS software (Integrated Botanical Information System), which provides data storage, data analysis and data exchange
\end{abstract}

Keywords: China; forest; grassland; high mountain vegetation; IBIS software; Kazakhstan; Russia; Siberia; zonal and intrazonal vegetation.

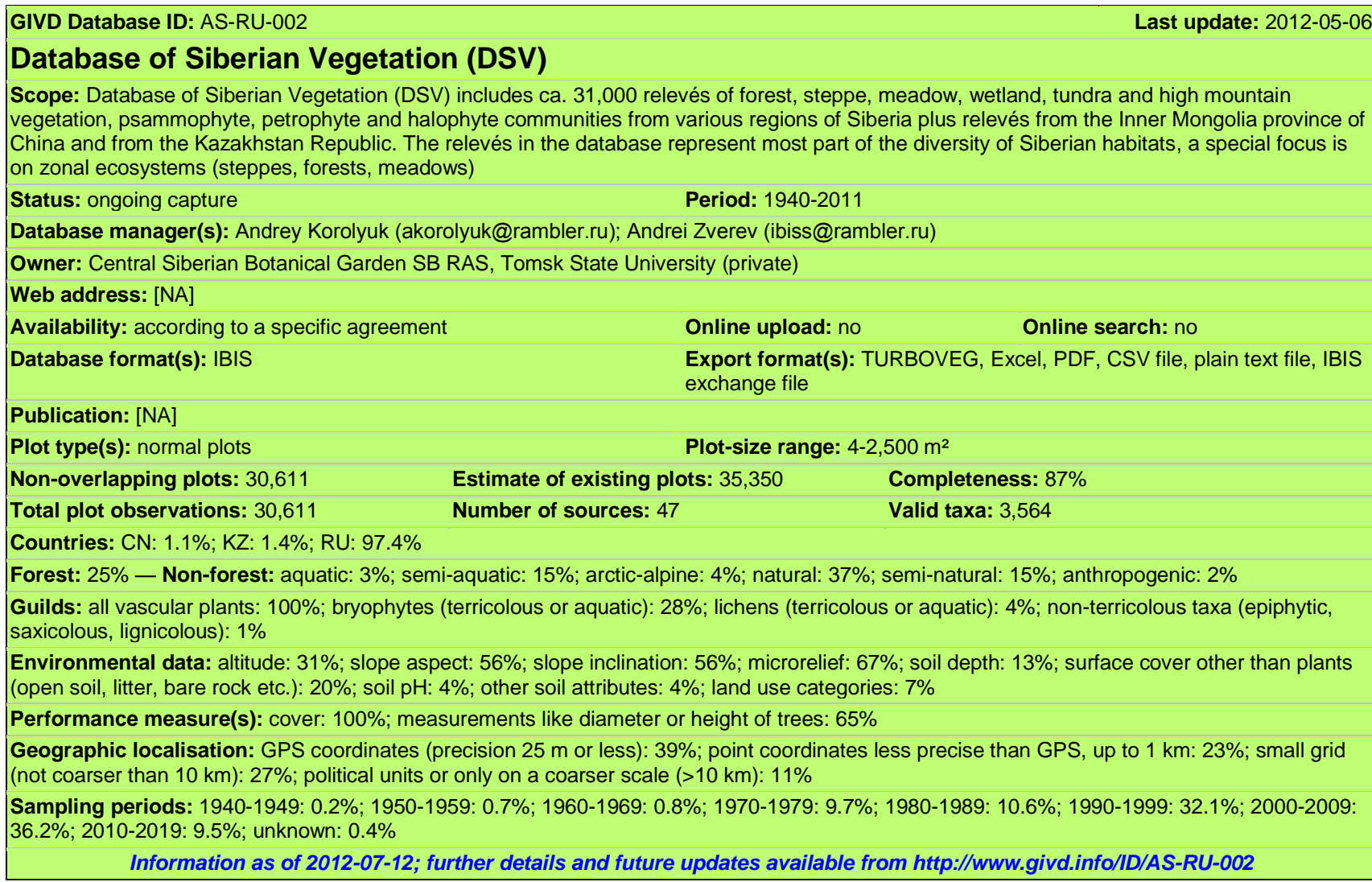

Andrey Korolyuk (akorolyuk@rambler.ru)

Geosystem Research Laboratory, Central Siberian Botanical Garden SB RAS, Zolotodolinskaya str. 101, 630090 Novosibirsk, RUSSIA

Andrei Zverev* (ibiss@ rambler.ru)

Department of Botany, Tomsk State University, Lenin str. 36, 634050 Tomsk, RUSSIA

*Corresponding author 